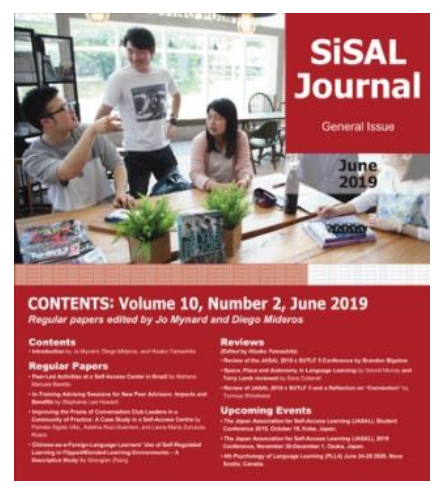

Studies in Self-Access Learning Journal

http://sisaljournal.org

\title{
In-Training Advising Sessions for New Peer Advisors: Impacts and benefits
}

ISSN 2185-3762

Stephanie Lea Howard, Ankara Yildirim Beyazit

University, Ankara, Turkey

Corresponding author: steffeee89@gmail.com

Publication date: June, 2019.

\section{To cite this article}

Howard, S. L. (2019). In-Training advising sessions for new peer advisors: Impacts and benefits. Studies in Self-Access Learning Journal, 10(2), 156-164.

\section{To link to this article}

http://sisaljournal.org/archives/jun19/howard

This article may be used for research, teaching and private study purposes. Please contact the author for permission to re-print elsewhere.

Scroll down for article. 
SiSAL Journal Vol. 10, No. 2, March 2019, 156-164.

\title{
In-Training Advising Sessions for New Peer Advisors: Impacts and Benefits
}

\author{
Stephanie Lea Howard, Ankara Yildirim Beyazit University, Ankara, Turkey
}

\begin{abstract}
This paper will describe the impact a series of advising sessions had on two university students being trained as peer advisors during the first half of a peer advising training course conducted at a self-access center in the Republic of Turkey. The author provides the rationale for developing the peer tutoring program, the selection procedure, and aspects of the training course. The paper will then focus on the learner development that occurred as a result of the trainees experiencing three advising sessions. The paper explores key training experiences, including insights and observations made by the trainer and trainees to illustrate how the development of the peer advisors was affected.
\end{abstract}

Keywords: peer mentoring, peer advising, self-access centers, learner development, learner confidence

This paper explores the impact that three advising sessions had on two students being trained as peer advisors at a self-access center at Ankara Yildirim Beyazit University (AYBU) in Ankara, Turkey. The sessions occurred during the first half of a peer advisor training program being developed at the author's institution. The factors that led to the creation of the program will be mentioned, including the rationale behind the selection of the two students and the requirement for both trainees to attend pre-training advising sessions. The paper will then focus on the learner development experienced by the two students as a result of two initial advising sessions, plus a third session that occurred later in the course. Key training experiences, and the resulting perceptions and observations of the trainer and the trainees will be utilized to indicate how the sessions affected the development of the students as peer advisors.

For the purpose of this paper, peer advising can be defined as the act of trained or more experienced students helping novice students with solving a problem or developing themselves further (Newton, Ender, \& Gardner, 2010). At the author's institution, peer advisors (PAs) will be working individually with students on a one-on-one basis. Students being trained as peer advisors within the Peer Advisor Program (PA Program) at AYBU will be referred to as 'trainees' or 'PA trainees' throughout this paper to designate their incomplete training status. All 
SiSAL Journal Vol. 10, No. 2, March 2019, 156-164.

trainees receive instruction from a learning advisor (LA), "a language learning specialist who works with learners on their personal language learning achievements" (Kato \& Mynard, 2016, p. 24) who is alternately referred to as 'trainer' or 'advisor' in this paper. Upon course graduation, PA trainees will be recognized with the title of Peer Advisor (PA) within AYBU and will be expected to use the skills and techniques they acquired during training to help students currently enrolled in the English preparatory program at the School of Foreign Language (SFL) at AYBU. It is anticipated that the PAs will help their peers for the remainder of the academic school year within a self-access center (the Independent Resource Center - ILC), located on the SFL campus. Any PAs that choose return for a second year of voluntary service will be recognized with the title of Senior Peer Advisor (SPA).

\section{Background and Context}

The principle motivating factors behind the decision to create the PA Program at AYBU were two-fold: (1) the desire to motivate current preparatory students through the use of student role models who exhibited confident English skills; and (3) as suggested by Gardner and Miller (1999), Newton, Ender, and Gardner, (2010) and Papadima-Sophocleous (2013), the need to provide a source of highly trained student volunteers who as volunteers would provide additional advising help in the ILC without adversely impacting the fixed budget assigned to the School of Foreign Languages.

\section{Rationale behind the selection of the first two PA trainees}

The PA trainees were informed that this was a pilot study and as such, their efforts and experiences would help establish the contents of the PA training program. Additionally, upon completion, they would become the first two PAs at the School of Foreign Languages at AYBU.

The decision to select these students resulted from the tremendous drive and motivation they both continued to display after they graduated from the English preparatory school. As AYBU department students, they returned to the ILC and hosted activities as volunteers which enabled them to acquire experience in a leadership role, act as student role models, and achieve a notable level of autonomy. In short, they displayed the exact qualities the PA Program desired to achieve in PAs. A hypothesis soon formed: the best time to create a PA Program and a PA training course is when the ideal candidates are available and willing to participate. 
SiSAL Journal Vol. 10, No. 2, March 2019, 156-164.

\section{Rationale behind requiring PAs to attend pre-training advising sessions}

The decision to require PA trainees to attend two initial advising sessions emerged as the most viable solution to an early problem: how can PAs be instantly exposed to the culture of what learning advising is and how it is conducted at AYBU so that the PA trainees become personally invested in the training process and passionate about their future role as PAs in the ILC? Moreover, it was thought that experiencing advising sessions from the perspective of an advisee would foster an innate understanding of how advising works and how it benefits an advisee.

\section{Experiencing an Advising Session as a First Time Advisee}

In addition to the above stated goals, the first advising session sought to confront an early trainee concern: What is the least awkward way to consistently begin an advising session with a presumed stranger? This was addressed through a discussion of a Needs Analysis Assessment Form (Thornton 2010, pp. 266-267) which both trainees had completed prior to the session. Reviewing and discussing this form provided a neutral starting point which both trainees could later replicate as a PA. The trainees later reflected that they enjoyed discussing their responses to this form as they felt reviewing a 'worksheet' was a familiar, comforting task to a student. It also directed them to consider their learning goals and themselves as learners in new, interesting ways which alleviated a fear of the unknown both had been hiding from the advisor. This in turn enabled them to deeply empathize with the nervousness often experienced by first time advisees.

Later in the session, one of the trainees experienced a profound aha moment, defined by Kato and Mynard (2016, p. 24) as "a pivotal moment in an advising session where a learner (or advisor) suddenly reaches a deep sense of understanding about a significant factor." This occurred when the trainer directly and indirectly presented some key training concepts, namely (1) a direct discussion about what advising is and is not; (2) how basic advising skills such as mirroring, restating, summarizing, and complementing are used to build rapport and trust between an advisee and an advisor (Kato \& Mynard, 2016), and finally, (3) discerning how the utilization of intentional reflective dialogue (Kato \& Mynard, 2016) while discussing how skillbased problems often assist in the discovery of the real, underlying issue.

In the extract below, the trainee discovers her real, underlying issue and is forced to admit it is not the issue she had originally identified. This realization is pivotal as the trainee had 
previously rejected the idea that the real problems experienced by students often do not match their self-identified problems.

(Extract from a trainee's first advising session)

\begin{abstract}
Advisor: We tell new advisees....I'm not a learning coach, I'm not going to teach you specifically reading skills or writing skills or things like that, but we can TALK about things like that because often times, like you started out saying 'I have a speaking problem I'd like to get better at / I have a writing problem I'd like to get better at' but as we talked, it wasn't actually a writing problem or a speaking problem, was it? Trainee: No [shakes head] Advisor: What was it? What do you think it was? Trainee: It was my fears.
\end{abstract}

\title{
Experiencing a Second Advising Session as a Repeat Advisee
}

One week later both trainees experienced a continuing advising session as advisees. Prior to the session, the trainees had expressed concern that holding a repeat session with an advisee would be difficult or embarrassing without the use of a Needs Analysis form to act as a starting point. In response, the trainer demonstrated how reviewing material from a past advising session could be utilized to construct a metaphorical bridge between the past and current session and to inspire a deep level of reflection.

This strongly affected one trainee when she reviewed a video she recorded in response to a challenge issued in the first session. In the video, the trainee is holding a conversation directly in front of her phone as it is recording as part her self-realized plan to overcome a fear of public speaking. During her reflection, the trainee discovered the source of her public speaking problem originated from a perceived inability to control the situation as evidenced by her initial avoidance of the camera. Later in the video, the trainee can be seen increasingly acknowledging the camera, which she attributed to a feeling of relaxation resulting from the understanding that she could gain control by deleting the video. This prompted her to realize she was recording this video for herself, a realization that influenced her sudden ability to make jokes and speak directly to the camera by the conclusion of the video. The deep reflection that resulted from a review of materials from the first advising session allowed the trainee to not only find the cause of her public speaking fear, but also her goal, her own solution for overcoming it. This enabled her to directly experience and internalize a key tenement of the advising process put forth by McCarthy (2009, p. 9) that advisors seek to "guide them [students] through a process of self-discovery towards that goal, so that they can become more autonomous learners." This is phrased by Newton, Ender, and Gardner (2010, p. 124) as "The role of a mentor is not to take over and just 
SiSAL Journal Vol. 10, No. 2, March 2019, 156-164.

tell the student what to do. Rather, you will ideally help students learn skills of problem solving so that in the future they are prepared for difficulties that come up and can deal with them on their own".

\section{The Third Advising Session: Mentoring Developing PAs to Address Self-Doubt}

The third session advising occurred near the end of the first half of the training course. It sought to address several rhetorical questions spoken about by the trainees which alluded to them possessing feelings of self-doubt and a fear of failure as a future PA. Examples of the questions posed include, 'What if the students don't like me?' and 'What if I am not any good?'

In following extract, Trainee 1 expresses concerns about disappointing her trainer and failing the training. (See the two comments marked in bold typeface below.) Trainee 2 agrees.

\section{(Except from the third advising session)}

Trainee 1: But when we are talking right now, it seems too serious for me and I'm not sure that I can make it. I mean, there is a some part inside of me that is saying 'you can do it, you can do it' and even if they don't -even if you can't see it, nobody will know it and [unintelligible]. Sometimes I still get nervous about if I fail, and, uh, make you disappointed.

Trainer: I think the best way for you to disappoint me would be for you to go through the entire training and then NOT come back-

Trainee 1 and 2: [loud laughing outburst] Trainer: THAT would be really disappointing.

Trainee 2: [still laughing but trying to talk anyway.] You will never know-.

Trainee 1: [still laughing but trying to talk anyway.] I mean like-I mean, the part, it's not about me, it's about ILC. If I make it wrong, it will be inside of it because you [points to Trainer] are inside of it, [name redacted] teacher is inside of this, [name redacted] teacher is inside of this... and... I... am afraid of making it bad.

One week later, both trainees revealed that they had recently conducted themselves as PAs outside of any training situations. This occurred when they acted as PAs to a student acquaintance. Initially, the trainees reported that they were dispensing 'advice-giving' (Newton, Ender, \& Gardner, 2010, p. 97), but as they became aware of this, they mentioned they switched to their advisor training. They began asking open-ended questions, using means of interpersonal communication, combined with the macro and micro skills of language counseling as outlined by Kelly (1999) and basic advising strategies to successfully help the student determine what the real problem was. More importantly, the trainees expressly stated that while advising, they accepted the fact that the student needed to determine their own answer, even if it was not the answer that the trainees personally wanted (Curry \& Watkins, 2017; Kato \& Mynard, 2016; 
Mynard \& Kato 2018). This contrasted with the view of advising and advisors that the trainees had initially reported prior to experiencing their advising sessions, that advising and advisors as experts functioning as problem solvers and resource providers (McCarthy, 2009).

The trainees admitted that prior to experiencing the mentoring session, they felt they would have reverted to dispensing advice and would have instructed the student according to their own beliefs and ideals. It appears that the mentoring session fundamentally inspired a new sense of confidence and accomplishment in the trainees which directly influenced their ability to conduct themselves as PAs a few days later.

\section{Final Observations and Thoughts}

Later reflections with the trainees highlight their belief that the initial advising sessions critically changed their perceptions of what advising was, how it could benefit advisees, and how the skills learned could impact their life in a positive way that emanated beyond the classroom. Both stated that all future PA trainees should begin by experiencing their own advising sessions if they have not already availed themselves of the advising services offered at AYBU. Specifically, the trainees worried that without these sessions, future PAs would continue to see advising as an abstract concept, thus rendering them incapable of completely resonating with their own advisees.

As stated previously, both trainees reported noticing that the advising sessions had affected their daily lives beyond the confines of training situations. In the following extract, one of the trainees reflects upon one of her milestones, when she observed that the advising sessions had changed her way of thinking and that this change was noticed by her friends.

Trainee: Before the advising, as I said, I was like people who say "Do it, do something what I say" like, because they are emotional break down .... and [I] am emotionally strong from in that situation, I can say healthy things, but... I realize that it doesn't matter what I say because if I say something about like "Do it, if you do something like this, you will be more happy" I don't know if she will be happy. She will be just [incomprehensible] maybe she will still be unhappy for that because it is my way to do something, to be happy-

Trainer: - Right. And your way may not be her way.

Trainee: Yeah. And now I am helping them with the questions, so like 'what, when, where, why,'... [The trainee roleplays a conversation she had with her friends where they ask her if she has realized she has changed because when they ask her for advice, she responds by asking them a lot of questions.]

Trainer: Oh, ok, so what you are saying there is, you mean that when you're taking to your friends, you're speaking a lot less?

Trainee: Um-hmm

Trainer: You are just asking them questions and making them speak a lot more?

Trainee: Yes, Yes. And that's the secret to like, now how I see their problem. 
SiSAL Journal Vol. 10, No. 2, March 2019, 156-164.

Conversely, the events of the third advising session underscored the importance of including a later, in-training advising session that allowed trainees to discuss their concerns in a way that fostered confidence as developing PAs. Both trainees clarified that their concern and self-doubt arose from a temporary inability to see the positive things they were achieving. They stated they had internalized the importance of asking questions rather than giving advice and this resulted in an inward reflection where they began to ask themselves numerous questions about their lives and their progress as developing PAs. Moreover, they became so distracted by the negativity inherit in these questions that they became blind to the incredible progress they had made as PAs. The chance to discuss these concerns, to remember their progress and achievements, reestablished their confidence as developing PAs and by extension, inspired them to conduct themselves as true PAs outside of training situations for the first time.

\section{Conclusion}

It is important to note that this is a work in progress that reflects key insights and training moments that occurred during the first half of AYBU's first ever Peer Advisor Training Course. Their experiences and observations match those of the trainer: including advising sessions as a regular part of a peer advisor training appears to be fundamental. The sessions directly provide a means to facilitate many of the goals outlined in the training course. Specifically, the two pretraining sessions allow trainees to acquire an innate understanding of what advising is, from the perspective of both advisee and advisor. It also provides numerous reference points for a trainer to use when explaining key concepts later in the training course. For example, in addition to directly introducing terms such as 'restating and summarizing', the trainer can draw from specific instances of those same techniques having been used during the trainees' initial advising sessions. It is possible that this allows for a more comprehensive understanding and increased training retention since the concept being introduced is no longer abstract in nature. Similarly, the inclusion of a third advising session near the midpoint of the training course is important to alleviate normal training concerns and re-affirm confidence in developing PAs.

The two trainees are halfway through the training program and they have already transitioned from excited yet nervous students, to confident, posed peer advisors, something that was not expected to happen so soon. It is currently unknown if this was indicative of their personalities or particularly of their longtime background experience as ILC volunteers and this should be noted as a possible limitation in this paper. The trainer has some concerns that future 
PAs possessing the same commitment level or natural ability as these two young women may not be found. Therefore, further PA training courses investigating the impacts of experiencing advising sessions on the developments of PAs will need to be conducted. Moreover, it would be interesting repeat this study with PAs who do not have a strong volunteer background in an attempt to ascertain how or if this affects the outcome.

\section{Acknowledgement}

This work was supported by the Scientific Research Fund (BAP) at Ankara Yildirim Beyazit University, Turkey, as part of Project 3934 in the 2017-2018 academic year.

\section{Notes on the Contributor}

Stephanie Lea Howard is the Co-coordinator of the Learning Advisory Program (LAP), the assistant coordinator of the Independent Learning Center (ILC), and an EFL instructor and learning advisor at AYBU-SFL. Her interests include advising in language learning, shadowreading, and designing EFL board games.

\section{References}

Curry, N., \& Watkins, S. (2016). Considerations in developing a peer mentoring programme for a self-access centre. Studies in Self-Access Learning Journal, 7(1), 16-29. Retrieved from https://sisaljournal.org/archives/mar16/curry_watkins/

Gardner, D., \& Miller, L. (1999). Establishing self-access: From theory to practice. Cambridge, UK: Cambridge University Press.

Kato, S., \& Mynard, J. (2016). Reflective dialogue: Advising in language learning. New York, NY: Routledge. Retrieved from https://www.researchgate.net/publication/330277953_Reflective_Dialogue_Advising_in Language_Learning

Kelly, R. (1996). Language counselling for learner autonomy: The skilled helper in self-access language learning. In R. Pemberton, E.S.L. Li, W.W.F. Or, \& H. Pierson (Eds.), Taking control: Autonomy in language learning (pp. 93-113). Hong Kong: Hong Kong University Press.

McCarthy, T. M. (2009). Dear Advisor: A look into the world of advising. Learning Learning 16(1), 8-14. Retrieved from https://www.academia.edu/790300/What_learning_advisors_do 
SiSAL Journal Vol. 10, No. 2, March 2019, 156-164.

Mynard, J., \& Kato, S., / Kanda University of International Studies. (2018). Courses 1, 2, 3, and 4: RILAE Advisor Education. https://kuis.kandagaigo.ac.jp/rilae/education/courses/

Newton, F., Ender, S., \& Gardner, J. (2010). Students helping students: A guide for peer educators on college campus. San Francisco, CA: Jossey-Bass.

Papadima-Sophocleous, S. (2013). Davids still exist among Goliaths: A story of modest selfaccess centre establishment and survival in times of economic decline. Studies in SelfAccess Learning Journal, 4(4), 281-294. Retrieved from http://sisaljournal.org/archives/dec13/papadima-sophocleous

Thornton, K. (2010). Supporting self-directed learning: A framework for teachers. Language Education in Asia 1(1), 158-170. Retrieved from http://www.leia.org/LEiA/LEiA\%20VOLUMES/Download/LEiA_V1_2010/LEiA_V1_1 4_Thornton_Supporting_Self_Directed_Learning_A_Framework_for_Teachers.pdf 